\title{
Effect of parallel surface cuts on bonding to dentine
}

\author{
W.J. O’Brien*, C.L. Groh and S.E. Strawn ${ }^{\dagger}$ \\ Specialized Materials Science Research Center, The University of Michigan, $1011 \mathrm{~N}$ \\ University, Ann Arbor, MI 48109, USA \\ (Received 21 December 1993; revised 11 April 1994)
}

\begin{abstract}
The strength of adhesive joints has been found to result from combinations of micromechanical, chemical and diffusion components depending on the system 1 . The development of adhesives that bond dental restorative materials to human dentine has been a major advance in the science of dental materials. The purpose of this investigation was to study the contribution of parallel surface cuts on the joint strength of dentine adhesives. Half of the specimens were finished with 60 grit $\mathrm{SiC}$ paper as a control. The other half were polished with 600 grit $\mathrm{SiC}$ paper and then finished with an instrument that produced a series of parallel surface cuts. A two-way analysis of variance showed that both the surface preparation and the adhesive system had a significant effect on shear bond strength $(p<0.0001)$. In general, the samples finished with parallel surface cuts gave shear bond strength values about double those finished with silicon carbide alone. For those control samples prepared with a 60 grit surface, the predominant type of failure was at the tooth/adhesive interface. The majority of samples with parallel surface cuts failed cohesively within the adhesive system. The experimental instrument is designed to produce retentive grooves or undercuts in the dentine surface which enhance micromechanical adhesion.
\end{abstract}

(Keywords: micromechanical adhesion; bonding agents; dentine; surface finishing; finishing tool; bond strength)

\section{INTRODUCTION}

The development of materials that bond to teeth has been a major advance in the science of dental materials. Several advantages include the opportunity to use more aesthetic restorative materials and more conservative cavity preparation techniques, and to inflict less trauma on the patient. The bond between the restorative material and the tooth structure can be a combination of mechanical retention and/or chemical bonds. The factors that contribute to mechanical and chemical adhesion have been described by Lee $^{2}$. The contribution of each of these mechanisms for adhesion to dentine is still a matter of speculation. Studies of the nature of the bond to dentine attained by some dentine bonding systems indicate that the bond is the result of diffusion of the adhesive into a hybrid zone ${ }^{3}$.

The longevity of a dental restoration is influenced by the quality and durability of the marginal adaptation. Many factors contribute to the quality of marginal adaptation and when these factors are used in optimum combinations, restorations resistant to mechanical and thermal stresses will be produced ${ }^{4}$.

\footnotetext{
* To whom correspondence should be addressed

${ }^{\dagger}$ Present address: Department of Restorative Dentistry, University of California San Francisco, San Francisco, CA 94143-0758, USA
}

The main factor of concern in this study is the surface preparation and resulting adhesion due to micromechanical attachment.

The development of adhesives that bond dental restorative materials to the dentine of human teeth has many clinical applications. The main advantages are that marginal leakage should be reduced and less tooth reduction is required to attain retention for filled resin restorative materials. There have been reports on the effect of surface preparation on the bond strengths to enamel ${ }^{5-8}$. Others have reported on the effect of surface roughness on the tensile and/or shear bond strengths to dentine ${ }^{8-11}$.

Improvements in bonding to dentine have been harder to establish, as they are generally lower and more variable than bond strengths to etched enamel. It was the purpose of this study to determine the effect of surface finish on relative bond strengths to dentine. Several commercial adhesive systems were chosen to test the hypothesis that there is a significant improvement in bond strength as a result of the enhanced micromechanical retention provided by a series of parallel surface cuts produced by an experimental instrument. The choice of adhesive systems was arbitrary since there are many commercially available materials and the specific formulations change rapidly. 


\section{EXPERIMENTAL}

The instrument for creating the parallel surface cuts is composed of a plurality of cutting edges which, when applied to a surface, forms a series of parallel cuts at an angle to the surface. The experimental instrument employed in this study is shown schematically in Figure la. It was prepared by mounting seven $6.5 \times 0.15 \mathrm{~mm}$ double-sided $100 \mu \mathrm{m}$ diamond discs (manufactured by Brasseler) on a $3.0 \mathrm{~mm}$ diameter mandrel separated by $3.15 \times 0.5 \mathrm{~mm}$ brass spacers.

Six groups of samples were prepared using the adhesive systems listed in Table 1. A mixture of freshly extracted human premolars and molars was disinfected with $5 \%$ sodium hypochlorite for $45 \mathrm{~h}$, rinsed in distilled water and pumiced. The teeth were stored in distilled water until they were mounted in Koldmount (manufactured by Vernon-Benshoff Co.). Half of the teeth were ground using wet 60 grit $\mathrm{SiC}$ polishing paper with random grit direction until an area of dentine at least $5 \mathrm{~mm}$ in diameter was exposed on the mesial surface. The other half were polished with wet 600 grit $\mathrm{SiC}$ polishing paper until the dentine was exposed as above and then finished with an experimental instrument designed to enhance bond strengths (see Figure la).

The instrument and each mounted sample were placed in a jig which limited the depth of the parallel surface cuts to $0.6 \mathrm{~mm}$. The surface cuts were placed parallel to the occluding surface of each tooth. Since the width of the cutting surface of the experimental instrument was $3.5 \mathrm{~mm}$, two passes, parallel to each other, were necessary to cut the $5 \mathrm{~mm}$ surface to be bonded. A tapered Teflon mould, which was $5 \mathrm{~mm}$ in diameter at the bonding interface, was clamped onto the surface prepared according to the recommendations of each manufacturer. The bonding agents were applied according to the procedures recommended for each material, including light curing as required. A button, $2 \mathrm{~mm}$ thick, of the corresponding restorative material was cured incrementally with a Command Light (manufactured by Kerr Manufacturing Co.).

The materials were placed in a random order to minimize technique bias. The mould was removed and the samples were stored in distilled water at $37^{\circ} \mathrm{C}$ for 7 days. The bonded samples were placed in a jig secured in the lower jaw of an Instron universal testing instrument. A wire loop, secured in the upper jaw, was used to apply a shear force, at a crosshead speed of $0.05 \mathrm{~cm} \mathrm{~min}^{-1}$, parallel to the dentine surface and per-
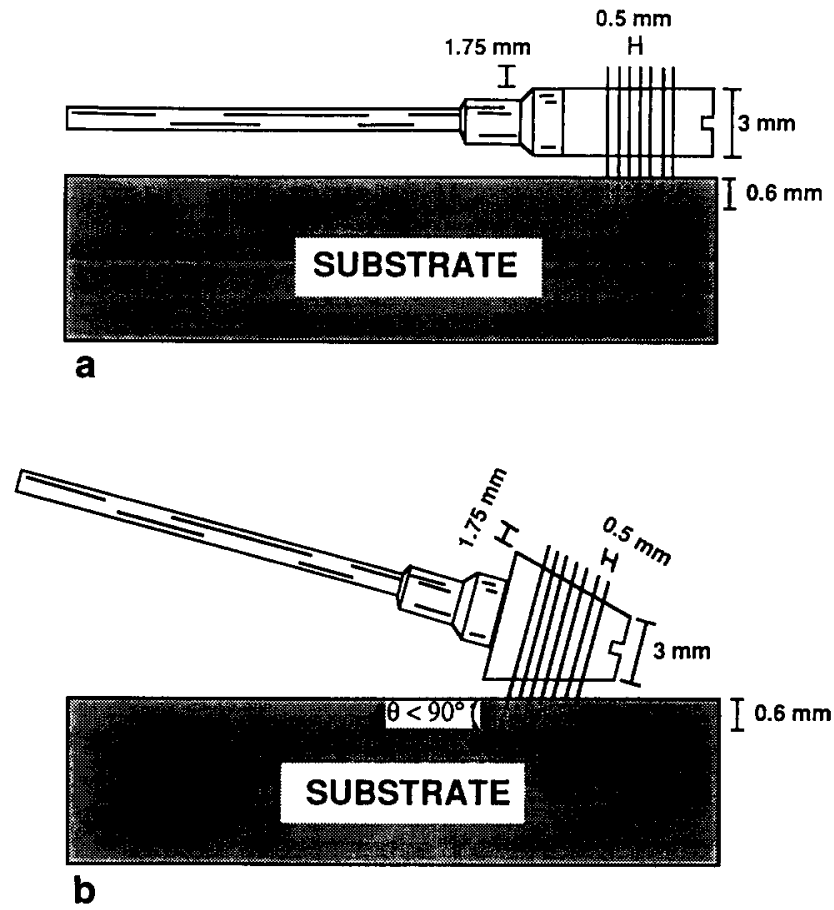

Figure 1 Prototypes of experimental instrument. (a) Prototype used in this study, having double-sided diamond discs of equal diameter that would produce cuts in the dentine perpendicular to the surface. (b) Proposed prototype, having double-sided diamond discs of varying diameters that would produce cuts in the dentine at an angle of less than $90^{\circ}$ to the surface

pendicular to the direction of the surface cuts (see Figure 2). The load at failure was recorded and the stress calculated. The method has been described by Munksgaard et al. ${ }^{12}$ and Sorensen and Dixit ${ }^{13}$. After failure, the surfaces were examined under a binocular microscope at a magnification of $20 \times$, to determine the type of bond failure.

Statistical analysis was performed using an analysis of variance to study the effects of surface preparation and adhesive system on the shear bond strength to dentine. The bond strengths were compared using the Tukey's studentized range (HSD) test to determine if a significant difference existed at the $95 \%$ confidence level (SAS statistical software, version 5.16, SAS Institute Inc., Cary, NC).

\section{RESULTS AND DISCUSSION}

The shear bond strength results are given in Table 2 and Figure 3. The analysis of variance results are given

Table 1 Adhesive systems used in this study

\begin{tabular}{|c|c|c|}
\hline Manufacturer & Bonding agent (chemical type) & Restorative material \\
\hline Johnson \& Johnson Dental Care Co., New Brunswick, NJ & Light Curing Dentin-Enamel Bonding Agent (phosphate ester) & Adaptic II \\
\hline Caulk/Dentsply, Milford. DE & Prisma Universal Bond (phosphate ester) & Ful-Fil \\
\hline 3M Health Care, Dental Products Division, St Paul, MN & Scotchbond 2 (BISGMA/HEMA)" & Silux \\
\hline Den-Mat Corporation, Santa Maria, CA & Tenure (aluminium oxalate NPG-GMA/PMDM)" & Perfection \\
\hline Vivadent (USA), Inc., Tonawanda, NY & Dentin Adhesit (polyurethane) & Heliomolar \\
\hline Kerr Manufacturing Co., Romulus, MI & Bondlite (phosphate ester) & Herculite XR \\
\hline
\end{tabular}

"Bisphenol-A-glycidylmethacrylate/2-hydroxyethyl methacrylate

${ }^{b} \mathrm{~N}$-phenylglycine and glycidylmethacrylate/pyromellitic acid diethylmethacrylate 


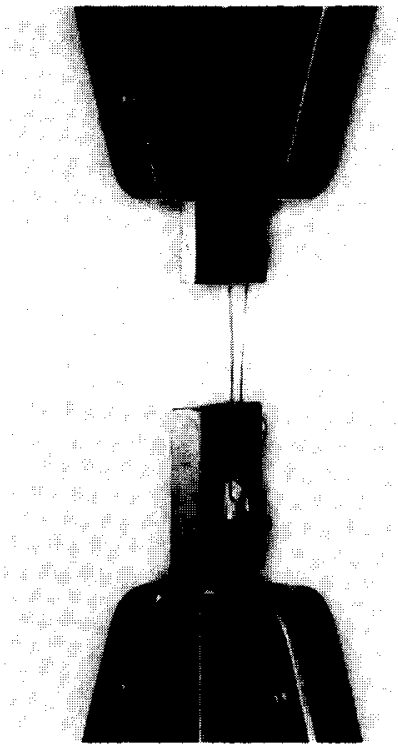

Figure 2 Specimen positioned in the jaws of Instron universal testing instrument prior to application of shear stress

in Table 2a. Results of the two factor analysis of variance showed that the shear bond strengths are highly dependent on both the surface preparation and the adhesive system used $(p<0.0001)$ but that interactions were not significant $(p=0.238)$. Therefore, a pair-wise comparison was conducted to rank order the results for the combination of surface preparation and the adhesive system used. For all adhesive systems tested, the bond strengths for the samples finished with the experimental instrument were about double those finished with the 60 grit $\mathrm{SiC}$ paper. The J \& J, Caulk and $3 \mathrm{M}$ materials in conjunction with the experimental instrument provided the highest shear bond strengths to dentine.

The shear bond strengths to the dentine controls obtained in this study are comparable to those reported in an earlier study by Barkmeier and Cooley $^{14}$. After $24 \mathrm{~h}$ at $37^{\circ} \mathrm{C}$, they measured a shear bond strength of $6.8 \pm 3.3 \mathrm{MPa}$ for the $\mathrm{J} \& \mathrm{~J}$ DentinEnamel Bond/Adaptic II system, $6.5 \pm 3.3 \mathrm{MPa}$ for the Caulk Prisma Universal Bond/Ful-Fil system, $8.8 \pm 3.4 \mathrm{MPa}$ for the $3 \mathrm{M}$ Scotchbond $2 /$ Valux system, $3.2 \pm 3.8 \mathrm{MPa}$ for the Vivadent Dentin Adhesit/ Heliomolar system and 1.7 $\pm 1.6 \mathrm{MPa}$ for the Kerr Bondlite/Herculite XR system. The only discrepancy between their data ${ }^{14}$ and the data measured in this study was for the shear bond strength of $13.4 \pm 3.8 \mathrm{MPa}$ that they reported for the Den-Mat Tenure (2-Step)/Marathon One system.

The frequency of failure types for the various adhesive systems using the two surface preparations are given in Table 3. For those samples prepared with a 60 grit surface, the predominant type of bond failure was at the tooth/adhesive interface. The majority of samples prepared with the experimental instrument failed cohesively within the adhesive system. Therefore, for the control samples the weakest site was the interface between the tooth and the adhesive system. For the samples with the retentive surface cuts, the shear bond strength was limited by the cohesive strength of the adhesive system. It was hypothesized that this improvement in strength and the change in type of bond failure was due to an increase in micromechanical retention.

Now that the feasibility of this concept has been demonstrated, the next step would be the design of dental burs which can produce parallel surface cuts. Also of interest is the design illustrated in Figure $1 \mathrm{~b}$. If the cuts are formed at an angle which is less than $90^{\circ}$, undercuts would be formed which might further enhance the micromechanical engagement between the

Table 2 Comparison of shear bond strengths (in MPa; mean $\pm \mathrm{SD}$ ) as a function of surface preparation ${ }^{a}$

\begin{tabular}{|c|c|c|c|c|c|}
\hline \multirow{2}{*}{$\begin{array}{l}\text { Adhesive system } \\
\text { Johnson \& Johnson }\end{array}$} & \multirow{2}{*}{$\begin{array}{l}\text { Surface preparation } \\
\text { Surface cuts }\end{array}$} & \multirow{2}{*}{$\frac{n}{10}$} & \multicolumn{3}{|c|}{ Bond strength (MPa) } \\
\hline & & & 15.3 & $(6.8)$ & \\
\hline Caulk & Surface cuts & 10 & 11.5 & $(2.4)$ & \\
\hline $3 \mathrm{M}$ & Surface cuts & 10 & 11.0 & $(3.1)$ & 1 \\
\hline Den-Mat & Surface cuts & 10 & 10.0 & $(2.5)$ & \\
\hline Johnson \& Johnson & 60 grit $\mathrm{SiC}$ paper & 10 & 7.12 & $(4.19)$ & 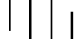 \\
\hline $3 \mathrm{M}$ & 60 grit $\mathrm{SiC}$ paper & 10 & 6.43 & $(4.84)$ & \\
\hline Vivadent & Surface cuts & 10 & 6.39 & $(2.21)$ & 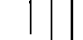 \\
\hline Kerr & Surface cuts & 11 & 5.66 & $(3.15)$ & \\
\hline Caulk & 60 grit $\mathrm{SiC}$ paper & 12 & 5.36 & $(1.71)$ & \\
\hline Den-Mat & 60 grit $\mathrm{SiC}$ paper & 11 & 3.99 & $(2.85)$ & \\
\hline Vivadent & 60 grit $\mathrm{SiC}$ paper & 10 & 3.38 & $(2.15)$ & \\
\hline Kerr & 60 grit $\mathrm{SiC}$ paper & 11 & 0.831 & $(0.491)$ & \\
\hline
\end{tabular}

"Groups joined by vertical lines are not significantly different using Tukey's studentized range (HSD) test at the 95\% confidence level

Table 2a Analysis of variance

\begin{tabular}{lcccc}
\hline Source & Sum of squares & Degrees of freedom & Mean square & $F$-ratio \\
\hline Between surface preparation & 925.479 & 1 & 925.479 & 82.011 \\
Between restorative systems & 853.402 & 5 & 170.68 & 1 \\
Interaction & 77.734 & 5 & 15.547 & 15.125 \\
Error & 1275.186 & 113 & 11.285 & 1.378 \\
\hline
\end{tabular}


surface and the solidified adhesive material. Ideally, the grooves or undercuts would be dimensioned in response to the viscosity characteristics of the fluid adhesive material so as to promote flow of the fluid adhesive material into the grooves or undercuts by capillary action and thus ensure complete penetration. Upon solidification of the adhesive material, the micromechanical attachment would be formed.

This study demonstrates an improvement of shear bond strengths of six adhesive systems to dentine that were finished with an experimental instrument compared to the control samples. Examination of the surfaces under magnification after failure indicated that the majority of those samples prepared with the experimental instrument had cohesive failure within the adhesive system which was sheared at the tooth surface. It was hypothesized that the parallel surface cuts produced projections of the adhesive material into the dentine that helped resist the shear forces perpendicular to those surface cuts.

\section{CONCLUSIONS}

The relative in vitro bond strength to dentine of six dentine adhesive systems was improved by the new surface finishing method described in this paper. The samples finished with a series of parallel retentive cuts gave shear bond strength values about double those

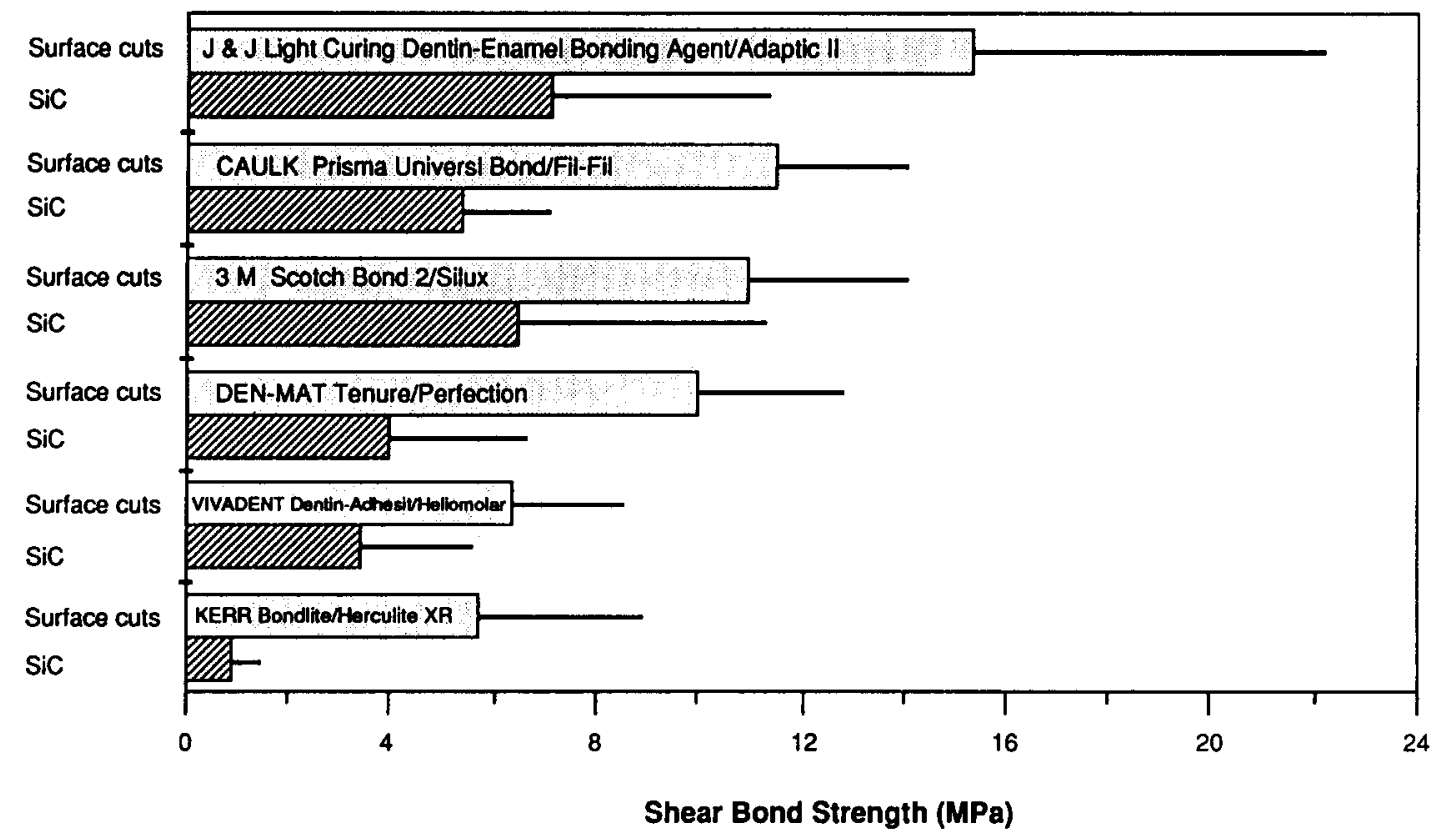

Figure 3 Mean shear bond strengths and standard deviation as a function of surface preparation

Table 3 Frequency of failure type

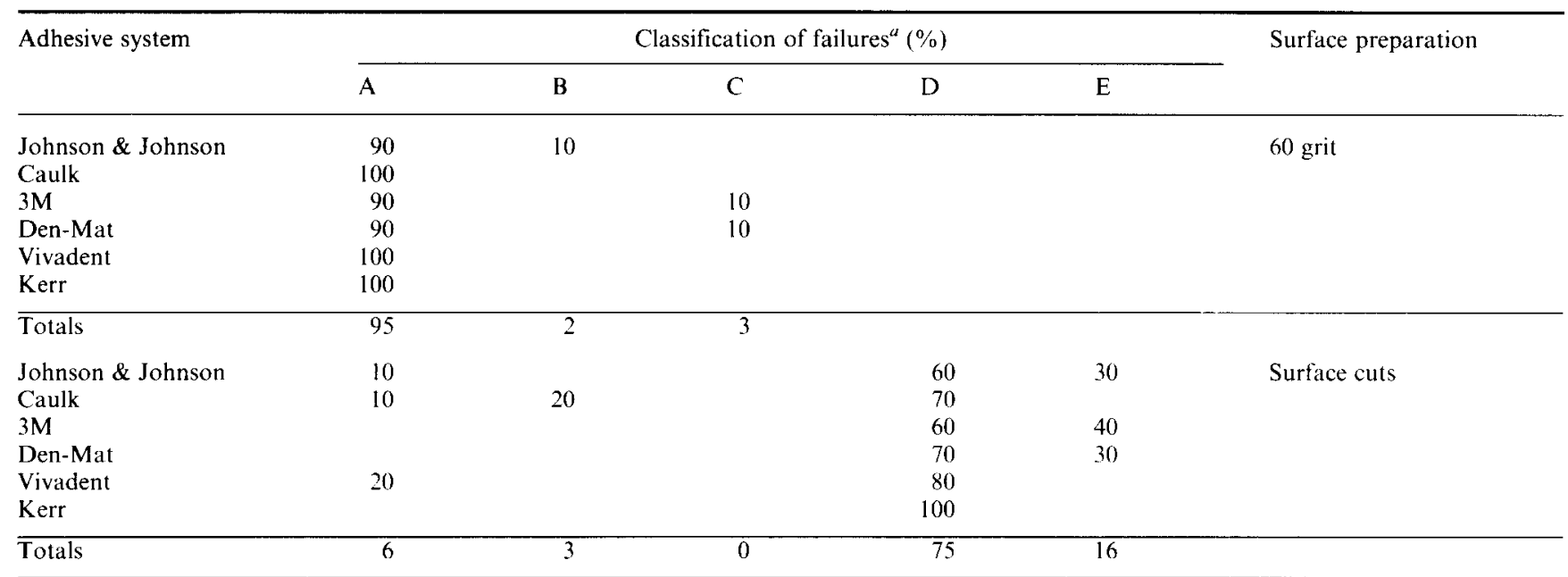

\footnotetext{
"A $=$ tooth/adhesive interface

$\mathrm{B}=$ mixed (interfacial + cohesive within adhesive system)

$\mathrm{C}=$ mixed (interfacial + cohesive within tooth)

$\mathrm{D}=$ cohesive within adhesive system

$\mathrm{E}=$ mixed cohesive (adhesive system + tooth)
} 
finished with silicon carbide alone. The experimental instrument is designed to produce retentive grooves or undercuts in the dentine surface which enhance micromechanical adhesion.

\section{ACKNOWLEDGEMENTS}

The authors appreciate the materials generously donated by Caulk/Dentsply, Den-Mat Corporation, Johnson \& Johnson Dental Care Co., Kerr Manufacturing Co., 3M Health Care, and Vivadent (USA), Inc. This investigation was supported by grant DE09296 from the National Institute of Dental Research, National Institutes of Health, Bethesda, MD 20892, USA.

\section{REFERENCES}

1 Wake, W.C. 'Adhesion and the Formulation of Adhesives', 2nd Edn, Applied Science Publishers, London, UK, 1982

2 Lee, H. in 'Dental Adhesive Materials Symposium' (Eds H.D. Moskowitz, G.T. Ward and E.D. Woodridge), New York University, New York, 1974, pp. 132-179

3 Wang, T. and Nakabayashi, N. 'Effect of 2-(methacryloxy)ethyl phenyl hydrogen phosphate on adhesion to dentin' J. Dent. Res. $1991,70,59$

4 Krejci, I. and Lutz, F. 'Marginal adaptation of Class V restorations using different restorative techniques' J. Dent. 1991, 19,24

5 Khanna, S.L. and Chow, J. 'Comparison of four composite materials and effect of tooth preparation on bond strength' ASDC J. Dent. Child. 1979, 46, 379

6 Aker, D.A., Aker, J.R. and Sorensen, S.E. 'Effect of methods of tooth enamel preparation on the retentive strength of acid-etch composite resins' J. Am. Dent. Assoc. 1979, 99, 185

7 Negm, M.M., Combe, E.C. and Grant, A.A. 'Factors affecting the adhesion of polycarboxylate to enamel and dentin' J. Prosthet. Dent. 1981, 45, 405

8 Tao, L., Pashley, D.H. and Boyd, L. 'Effect of different types of smear layers on dentin and enamel shear bond strengths' Dent. Mater. 1988, 4, 208

9 Mowery Jr, A.S., Parker, M. and Davis, E.L. 'Dentin bonding The effect of surface roughness on shear bond strength' Oper. Dent. $1987,12,91$

10 Finger, W.J., Manabe, A. and Alker, B. 'Dentin surface roughness $v s$. bond strength of dentin adhesives' Dent. Mater. $1989,5,319$

11 McInnes, P.M., Wendt Jr, S.L., Retief, D.H. and Weinberg, R. 'Effect of dentin surface roughness on shear bond strength' Dent. Mater. 1990, 6, 204

12 Munksgaard, E.C., Irie, M. and Asmussen, E. 'Effect of dentin surface roughness on shear bond strength' J. Dent. Res. 1985, 64, 1409

13 Sorensen, J.A. and Dixit, N.A. 'In vitro shear bond strength of dentin adhesives' Int. J. Prosthodont. 1991, 4, 117

14 Barkmeier, W.M. and Cooley, R.L. 'Laboratory evaluation of adhesive systems' Oper. Dent. 1992, Suppl. 5, 50 